\title{
The Case of Sharon Considered from the Vantage Point of Interpersonal Reconstructive Therapy
}

\section{KENNETH L. CRITCHFIELD, ${ }^{a, b, c}$ JULIA DOBNER-PEREIRA, ${ }^{a, c} \&$ ELIZA STUCKER ${ }^{\mathrm{a}, \mathrm{c}}$}

\author{
a James Madison University \\ ${ }^{\mathrm{b}}$ Correspondence regarding this article should be sent to: Kenneth L. Critchfield, 7401, Johnston Hall, Rm. 219,70 \\ Alumnae Drive, Harrisonburg, VA 22807. \\ Email: critchk1@jmu.edu \\ ${ }^{\mathrm{c}}$ The authors are grateful to the Brief Psychotherapy Research Project (J. Christopher Muran, Principal Investigator) \\ at Mount Sinai Beth Israel Medical Center, New York, for making available material on the case reported on in this \\ set of articles.
}

\begin{abstract}
In Interpersonal Reconstructive Therapy (IRT: Benjamin, 2003/2006; 2018) a case formulation is used to tailor interventions to each patient's unique patterns. Using the IRT lens, psychopathology is understood as reflecting attempts to adapt to current environments using maladaptive rules and values that were learned and internalized in the context of close attachment relationships. IRT identifies precise ways in which early learning shapes present experience. Additionally, the "gift of love" (GOL) hypothesis posits that motivation to repeat maladaptive ways is linked to the wish to receive love and acceptance from specific internalized attachment figures by repeating their ways and values for the patient. The IRT case formulation has been shown to be reliable and valid (Critchfield, Benjamin, \& Levenick, 2015). The therapy adherence measure is also reliable (Critchfield, Davis, Gunn, \& Benjamin, 2008) and correlates well with retention as well as reduced symptoms and rehospitalization rates (Karpiak, Critchfield, \& Benjamin, 2011) among "difficult to treat" patients characterized as having high levels of personality disorder, chronic and severe problems, and prior failed treatment attempts. To illustrate the case formulation process, an IRT formulation is applied to the case of a 28 -yearold female patient for whom a poor outcome was documented.
\end{abstract}

Keywords: attachment; case formulation, copy process theory: Structural Analysis of Social Behavior (SASB); Interpersonal Reconstructive Therapy; case study; clinical case study

In this paper we provide an overview of case formulation in Interpersonal Reconstructive Therapy (IRT: Benjamin, 2003/2006; 2018) using Sharon's case (Westerman \& Critchfield, $2021)$ as an example. Part of the challenge in doing this work, and its appeal to us, is to see whether a reasonable and coherent IRT case formulation can be constructed from therapy notes, transcripts, and the like, in the absence of the recommended interview process. This is important for ongoing IRT research because it could demonstrate feasibility of assessing whether IRT principles that have been linked empirically to outcome are also employed in other therapies and 
other psychotherapy data sets, since adherence to IRT principles flows directly from a tailored formulation. The sections that follow provide an overview of IRT theory, including the key role of an individual case formulation, how to construct one, and brief overview of validity data. The method of conceptualization is then applied to Sharon's case. Later sections address treatment goals in IRT as well as specific recommendations for Sharon's treatment. Readers who wish to have more depth than just the cursory overview of IRT formulation and treatment methods provided here are encouraged to consult additional resources, especially Benjamin, 2003/2006, Benjamin 2018, as well as the empirical articles cited in what follows.

\section{CASE FORMULATION}

\section{Basic Approach to Case Formulation}

\section{Interpersonal Reconstructive Therapy}

IRT theory is grounded in attachment, object-relations, and interpersonal theories, and emphasizes patterns learned with important caregivers. IRT clinicians are free to select specific interventions from any school of thought, or to innovate new ones, so long as they fit the individual formulation and help move toward the goals of treatment. As such, IRT is principlesbased, and integrative in its practice. An IRT therapist begins with the assumption that current problems and "disordered" patterns of behavior actually make sense when seen through the lens of rules, values, and experiences that have been internalized in close attachment relationships, however maladaptive the implications of that learning may be in the present. Often, pathology reflects continued yearning to show loyalty or otherwise win the love of the internalized attachment figures by continuing to play out maladaptive patterns and abide by their rules and values; treatment thus requires a process of active differentiation from these figures, to support learning and practicing new ways of being.

In practice, what is of particular salience to IRT clinicians are patterns with self and others that have demonstrable links to clinical symptoms and presenting problems. When these patterns themselves represent a copying of earlier relational patterns and themes, they constitute behavioral evidence that a key relationship has been internalized and likely plays a role in problem maintenance. Copying of this sort is often recognizable as repeated themes of observable relational behavior with others, or with the self. The copy processes are: identification, recapitulation, and introjection. Identification is acting like important person/s with whom the patterns were first learned. Recapitulation is behaving as if the important other is still present and in charge. Introjection involves treating oneself like the important person did. For example, if one's father was rigid and controlling about appearance, introjection of that pattern would involve parallel patterns of self-control in some domain of life that mirrors his rules and values, e.g., as perfectionistic judgment of the self in similar terms, which may in turn be linked to clinical problems such as, highly controlled eating, restriction of life options based on appearances and so on. The Structural Analysis of Social Behavior (SASB: Benjamin, 1979; 1996), described later in this paper, provides a measurement model and lens for determining whether precise repetition of specific interpersonal behaviors has occurred. In fact, observations with the SASB model to track repeating themes in client experience provides the foundation upon which the IRT method was developed. 
A general description of the process of developing a copy process-based case formulation is: (1) seeking to understand the symptoms or problems to be explained in the context of when and how they occur, (2) exploring associated patterns of relating with self and others in the present, (3) identifying copy process patterns that suggest the role of internalized figures, or "family in the head," (4) formulating hypotheses about likely attachment-based mechanism, or "gifts of love" (GOL) that fuel current repetition of problematic ways of being. The formulation should have direct implications for needed interpersonal and intrapsychic learning in the present, as well as providing a sense of what attachment-linked pressures might block or counter that optimal learning process. In other words, yearning desires for love, acceptance, and protection from internalized loved ones may ultimately need to be let go of, or otherwise reworked, to allow adoption of more adaptive ways of being. As Benjamin (2018) underscores, this process can involve significant grief and uncertainty since the change process involves reconstructing one's deepest notions of self and relatedness. The change process seeks to re-cue and make adaptive those elements in the learning history that have led to miscued understanding of what constitutes threat and safety, as learned through close attachment relationships and encoded biologically at the level of the autonomic nervous system.

In terms of specific techniques, Interpersonal Reconstructive Therapy (IRT) offers clinicians a framework to scaffold treatment and select techniques from a wide variety of sources to maximize outcome (Benjamin, 2003/2006; Critchfield, Benjamin, \& Levenick, 2015). A therapist can draw techniques from any tradition as long as they are responsive to relational processes in the present, are tailored to fit the patient's unique case formulation / learning history, and address needs appropriate to their stage in the change process. Adherent IRT therapists have been shown empirically to tailor their interventions in ways that reflect a mixture of psychodynamic/interpersonal, cognitive-behavioral, and humanistic/existential approaches (Critchfield, Mackaronis and Benjamin, 2017).

Red and Green Parts of the Self. IRT involves conceptualization of the self as having at least two parts, initially discussed with patients as "Red" and "Green." The Red self has been characterized as the "Regressive Loyalist" (Benjamin, 2003/2006) and more recently the "Yearning Self" (Benjamin, 2018), and is the part that seeks love, acceptance, and protection from internalized loves ones by repeating maladaptive rules and values learned with them. The Green self seeks healthy adaptation in the present that is reality-based and responsive to current circumstances. When clients begin therapy, maladaptive Red patterns learned with important figures are frequently driving current distress and symptomatology. Green patterns may also be present, but are blocked or overshadowed by Red, e.g. in a patient comment like, "I know I should feel happy after getting that raise and promotion, but I was never supposed to do this well, and I can't shake this feeling that I'm more of an imposter than ever." Sometimes Green ways of being were never provided, scaffolded, or encountered, and so have not yet been learned.

\section{Interpersonal Specificity of Copy Process Patterns.}

Interpersonal specificity is of crucial importance to the IRT formulation process. Copy process, to be inferred as present, must involve precise replication of early patterns. Often, these are observable clinically in the form of specific language or actions applied in the past and in the 
present. At a minimum, the repetitions must be identifiable using behavioral clusters/profiles from the Structural Analysis of Social Behavior (SASB: Benjamin, 1979; 1996). SASB is a wellvalidated descriptive model of interpersonal behavior. It facilitates specific description of intrapsychic and interpersonal behaviors and can be implemented in clinical or research settings. SASB has been operationalized as a questionnaire (Intrex: Benjamin, 2000) and as an observational coding system (Benjamin \& Cushing, 2000) that can be implemented by clinicians to understand clinical processes, including within sessions to recognize and address relational ruptures, enactment of copy process, and the like (Benjamin, 2003/2006; 2018; Critchfield \& Benjamin, in preparation). For Sharon, the current paper will emphasize observational uses that can be implemented readily by clinicians. Additional description of the implementation of SASB in its questionnaire form or as observational methods tailored for research or clinical use are available elsewhere (e.g., Benjamin, Rothweiler, \& Critchfield, 2006).

Structural Analysis of Social Behavior. The SASB model is built on three distinctions: Focus, Affiliation, and Interdependence. The Focus of a behavior might be on Others (transitive action to, for, or about others), Self (intransitive behavior that is to, for, or about the self in relation to others), or Introject (intrapsychic or behavioral self-treatment). Each behavioral focus is organized by two axes. The horizontal axis reflects degrees of affiliation from extreme hostility (far left) to extreme friendliness (far right). The vertical axis measures degrees of interdependence that range from extremes of enmeshment (bottom) to extremes of differentiation (top). Figure 1 shows the simplified cluster version of the SASB model (8 clusters of behavior per surface), which has commonly been used in IRT formulation work to date. Focus is represented by parallel labeling at each position around the model: Focus on Other, Self, and Introject are positioned as top, middle, and bottom of each respective stack.

Using SASB to Define Problem States and Therapy Goal Behaviors. Behaviors associated with symptoms and Red states typically involve hostility and/or extremes of enmeshment or differentiation (i.e., the vertical interdependence dimension), especially when rigidly held as a baseline or are out of context for normative circumstances. By contrast, Green, adaptive behaviors consistent with IRT therapy goals are represented on the right side of the SASB model. These ways of being involve context-appropriate friendliness with the self and in normative social settings, along with reciprocity of focus and moderate degrees of both enmeshment and differentiation. In other words, a healthy self shows a secure attachment pattern, even under stress, and consists of relating that is friendly (i.e., on the right side of the SASB model) and reciprocal in focus in ways that are responsive to context. Within that friendly region on the right of the model, IRT therapy goal behaviors include the ability to have a separate self as well as being able to coordinate and connect with others (i.e., moderate and flexible with regard to the vertical interdependence axis). Therapy goal behaviors thus occupy the 3 spatial clusters of behavior on the far right of Figure 1, a region of the model that has been termed the Attachment Group (AG: Benjamin, 2003/2006).

Single positions on the SASB model can be used to describe social behaviors contained in many patient narratives. Complex combinations are also common and involve simultaneous use of more than one SASB position, e.g., as might be found in double-bind communication, ambivalence, and so forth. To enhance use of the interpersonal model offered by SASB, Benjamin also developed a parallel set of models for affect and cognition that additionally help 
in tracking and contextualizing relational behavior (Benjamin, 1986; 2003/2006). For present purposes, only the behaviorally-focused SASB model will be invoked to illustrate case formulation for Sharon.

\section{$\underline{\text { Procedure for Arriving at a Formulation }}$}

The IRT Case Formulation Method typically involves conducting a comprehensive initial interview in order to understand presenting symptoms and problems in the present in terms of their interpersonal origins (Benjamin 2003/2006). In outpatient work this is woven into the therapy process of early sessions and so occurs over 3 to 10 sessions depending on case severity, stability, and specific needs. Benjamin also describes an intensive inpatient process involving a single 90-minute consultative interview.

Step One: Outlining Patterns in the Present. Relationship narratives that are linked to current symptoms are understood through three basic components: input from others or the world, patient's response to the input, and the impact on the patient's self-concept or selftreatment. As an algorithm these are organized as "input, response, and impact on self" with reciprocal, interactive links often occurring between each domain of experience. Experiences in each domain are characterized by their position on the SASB model.

Step Two: Identify Copy Processes. Once patterns are understood in the present, the interviewer explores prior experience with important attachment figures such as parents, teachers, lovers, or extended family members. The IRT clinician might reflect back a summary of current themes and go on to ask whether it is long-standing, or when it is first remembered, in order to help link the pattern to important figure(s).

As noted previously, there are three main copy processes in IRT that suggest internalization of relationship patterns. They are: identification (be like him/her), introjection (treat yourself as you were treated) and recapitulation, (act as if he/she is still here and in control). This step in the therapy process involves understanding current behaviors through a copy process lens. Identification means behaving like an important other; for example, a patient who witnessed their parent's alcoholism might neglect self as their parent did. Introjection involves treating oneself as an important other did. For example, self-control might mirror the actions of a controlling loved one. Recapitulation involves acting or perceiving the world as if an important other is still in charge. For example, one might wall off when they become close to another as if the other is their former abuser. Copy processes frequently co-occur. SASB provides a coherent frame for recognizing and understanding these patterns, and shows strong psychometric properties of reliability, sensitivity and specificity in doing so (Critchfield et al, 2015).

Step Three: Articulate the Gift of Love (GOL) Hypothesis. The gift of love is the concept that maladaptive patterns persist out of a yearning desire for love and acceptance from our attachment figures or their internalized representations. The idea is that we remain faithful to the rules and values learned with these important others in a continued attempt to get it right by them (Benjamin, 2003/2006). Awareness of this motivation is often difficult on first pass, as it can be painful to acknowledge. As such, it is typically offered initially as a hypothesis to explore 
collaboratively; a way of explaining how copy process themes may "make sense" and why they may occur. The example provided for Sharon's case should help with illustrating this element.

Step Four: Outline Treatment Implications. In general terms, IRT treatment includes several steps that begin with a relationship that seeks to collaboratively formulate maladaptive copy processes, making sense of their origins and link to current symptoms, and enabling the will to change. Over time, treatment shifts to block old problematic ways of being while learning and increasing use of adaptive ways in the present. This involves differentiating from internalized attachment figures when they block progress and moving through the GOL stages of change outlined by Benjamin (2003/2006; 2018). The emerging "green" self is known as the "Growth Collaborator" or "Birthright Self" that would have evolved given secure base conditions (Benjamin, 2008).

\section{Reliability, Specificity, and Sensitivity of the IRT Case Formulation Method.}

Reliability, specificity, and sensitivity of the IRT case formulation method were investigated by Critchfield et al (2015) in a sample of 92 patients with high severity and complex diagnostic profiles characterized as CORDS cases (Comorbid, Often Rehospitalized, Dysfunctional, Suicidal). By watching a subset of 20 recorded interviews conducted using the inpatient version of the recommended clinical interview process, trained observers were able to agree strongly about key attachment figures $(\mathrm{kappa}=.88)$, copy processes $(\mathrm{kappa}=.80)$, links between symptoms and attachment figures (kappa $=.78)$, as well the specific copy processes that formed the linkages $($ kappa $=.71)$. In addition, raters were able to use SASB to reliably characterize the central interpersonal elements perceived by raters (profile $r=.77$ ). Agreement was strong for cross-site comparisons, as well as for when trained, non-clinician undergraduates were used as raters, suggesting that IRT case formulation patterns are readily observed in consult interviews. The same work demonstrated that interpersonal formulation patterns (identifying information removed) could be uniquely matched to their source interviews. An implication of this work is that IRT case formulations do not derive their reliability from a one-size-fits-all stereotype about patient problems, but instead carry sufficient specificity in the linking of attachment figures, copied patterns, and presenting problems to allow formulation-based tailoring of treatment to individuals.

\section{The Formulation for Sharon's Case}

\section{Case Context and Approach to the Archived Data}

The patient selected for formulation, Sharon, came from an available psychotherapy archive that contains considerable information about presenting problems and their context, as well as other a range of measures focused on personality, symptoms, and functioning as noted in our separate paper detailing Sharon's presenting problems and relevant data (Westerman \& Critchfield, 2021). Notably missing in the materials, and a deviation from the recommended process for making an IRT case formulation (Benjamin, 2018; Critchfield, Benjamin, \& Levenick, 2015; Critchfield, Panizo, \& Benjamin, 2019) was direct review of the attachment history to explore for presence of copy process and GOL motivation. Part of our interest in the current project was to explore the feasibility of making an IRT case formulation in the absence of 
an interview that directly explored these elements. The reason this is of interest to us is that we believe that IRT principles are often invoked in multiple therapeutic schools. The ability to generate IRT formulations for patients seen in non-IRT treatment databases would make it feasible to empirically test whether attachment-based, IRT principles predict outcomes in whatever context they may be invoked.

In Sharon's case we discovered that sufficient detail was available from inspection of intake materials, clinical notes and session transcripts to allow, with some reasonable inference, a formulation of Sharon's current patterns and their precedence in her learning history with close others. Sharon's resulting formulation appears to us to be coherent and potentially helpful. While lacking in certain details it is "of a kind" with formulations produced in our work focused exclusively on IRT treatments (Critchfield et al, 2015).

Although the therapy ended long before our work to develop this formulation, the conceptualization that follows repeats some of the material provided in our initial summary of her circumstances to remind readers of relevant context It is written in present tense for ease of communication.

\section{Context and Presenting Concerns to be Explained by the Case Formulation}

Sharon is a 28 year old white female working as a social worker for disadvantaged children. She has no children of her own. Her presenting symptoms involve anxiety, along with diminished concentration and procrastination about work and a planned writing project. She was evaluated by SCID-I interview to have Anxiety NOS, with mild symptoms, and generally functioning well. SCID-II interview indicated that Sharon met criteria for Avoidant, Selfdefeating, and Paranoid personality disorders. Target complaints listed on her intake forms include (1) "still getting over" relationship loss of one and a half years ago, (2) "difficulty moving on and leaving the past behind." A third target complaint was identified mid-therapy and includes (3) "dealing with the attachments in my family." In interview notes she self-reports problems with anger and guilt. Central to Sharon's concerns, and a major element of therapy discussions we observed in transcripts and session summaries involves fact that she was engaged and planning to be married but called it off roughly one and a half years before beginning treatment.

Sharon had two prior treatment attempts. Each was in relation to the same presenting concerns involving the loss of her relationship, with the most recent treatment ending one month before seeking treatment in this study. The prior treatment ended a year before that. Each prior treatment lasted about four months. Sharon reported that she ended these treatments because they were not helping, were too expensive, and felt the therapists did not understand her. She also emphasized that both therapists said she should "move on" from the relationship with her exfiancé. Sharon has had no prior hospitalizations. She relies on her friends for support in times of need. She is not taking any medications.

Step One: Summarizing Sharon's Patterns in the Present

When Sharon began treatment, she reported receiving a variety of nonsensical emails from various accounts for over a year. She suspected that these were sent by her ex-fiancé. He 
denied being the source. However, their families had been close and at one point she asked her ex-fiancé's father about the emails. He appeared to confirm her suspicions. Sharon's father then tried to intervene "to protect" her by demanding that the ex-fiancé stop sending the emails that he denied sending. Since then, Sharon describes their two families as being "at war."

Regarding the emails, Sharon had gone as far as consulting professionals who have been unable to identify the sender. She reports "I get scared of the thought that maybe it's not him," "I can't stand the thought that someone feels the need to do this to me," "I will never know the truth", and "I can't accept the feeling of death between us." Friends, in response to her ruminations, have counseled her to change her email address, becoming frustrated with her when she doesn't. Sharon in turn perceives the friends as pressuring her, and so distances herself from them for long periods of time. In her second therapy session Sharon reports changing her email, but "deliberately didn't tell them," "I wanted them to get frustrated because they gave me such a hard time," and that she had plans to instead contact her ex-fiancé using the new email address. Sharon reports "I know if I got back with him it would upset everyone else." Yet, she hopes this is possible "so he wouldn't hate me" noting "he has hold on me, I don't know why" and does not pursue new relationships.

The relationship with the ex-fiancé began in her early 20's and lasted for a total of five years. The two were engaged for the last six months of this period, after he pressured her to get married. Sharon describes her ex-fiancé as having two personalities: one side was "loveable and caring" and the other side was "possessive and demanding." She reported that there was conflict within his family system, including his parents yelling at him for extended periods of 3 hours at a time, to which he responded with what appeared to Sharon to be a depressive episode. She also noted he had been physically aggressive to his sister on one occasion. During their relationship she worried and wondered about his welfare, as she still does now. The proximal circumstance for the break-up was that the ex-fiancé and his father had conflicts and the father reversed a previous offer to pay for the wedding. After an argument in the couple, Sharon insisted that her fiancé go to therapy before they married. He refused, and so Sharon cancelled the wedding four months before the planned event. She described ending the relationship as "the cruelest thing I could do" to him. Since then they have had encounters in which he has yelled at her publicly and shown that he blames her and remains very upset about the breakup.

In terms of Sharon's present self-concept. Formal assessment via the SASB-based Intrex Questionnaire (at intake) shows that when she is at her best, her profile is predominated by therapy goal behaviors of Self-Affirm, Self-Love, and Self-Protect-suggesting she has access to Green ways of being. However, when at her worst, the profile emphasizes behavior on the left side of the SASB model, especially Self-Blame, and Self-Neglect. These questionnaire-based characterizations are consistent with her documented narrative descriptions. For example, at work she reports feeling "competent and appreciated," "doing the best I can," and "feels smart" despite occasional doubts. However, she also feels "like a child in an adult job," and "afraid if I let go for a minute they could see through me." She describes herself as focusing with worry on the health of others (including ex-fiancé and father, among others), to the degree that she "obsesses" about "death, illness, endings, people growing apart and moving on." "I can't talk about illness ... especially someone I know ... death is along the same lines." She gives an example of worrying about her father traveling by plane even though he is healthy. She notes 
that the fear is part of her conscious rationale for not getting attached to others "what if something happens to them?" She reports long being her father's confidante about his conflicts with mother and notes that she feels closer and more aligned with him than is her sister, with whom she currently lives.

IRT and SASB-Based Summary of Sharon's Current, Symptom-Linked Patterns. The above information about Sharon's patterns in the present is organized and SASB-coded as shown in Table 1. To understand that display, it should be noted that an IRT formulation values interactive context. It is helpful to think in terms of three major components that provide that context: (1) inputs from the world, (2) Sharon's response or how she "meets the world," and (3) associated aspects of her self-concept/self-treatment. Inevitably, there are reciprocal links and patterns of interpersonal complementarity that knit these elements of the pattern together and make it stable. However, for formulation purposes, the goal is simply to identify how it works thematically in a way that allows detection of potential copy process links to attachment figures in Step 2.

As shown in Table 1, for Sharon, we identified two separable patterns. The first involves perception of loved ones (e.g., fiancé, friends) as controlling, judgmental, or intrusive, and unable to understand or meet her needs (a complex interpersonal message involving both perceived control and neglect). She responds in a way that is largely complementary to this input (i.e., occupies the same positions on the SASB model, but with opposite focus), complying in part, often resentfully, but also defying the perceived control of others by withdrawing. What is more, she uses withdrawal as a way to punish others, e.g., as when she changed her email address at the urging of friends, but then planned to give the new address to her ex-fiancé and not to them precisely because she felt pushed by them; another example is when she ended the engagement she felt pressured into because her boyfriend would not go to therapy. The mixed messaging is puzzling and frustrating to others. Sharon ends up depriving herself of healthy relationships, meanwhile wondering what is wrong with her or what she did to deserve their perceive mistreatment.

Table 1 also shows that the SASB-codes for her introjective self-treatment align with those identified previously on the Intrex questionnaire for when she is at her worst. Her presenting symptoms of anger, guilt, and anxiety all make sense in relation to this pattern, e.g., her anger appears to be in service of controlling others, guilt is present when she blames herself, and anxiety makes sense in light of her overwhelm about the intrusive control she perceives from others.

A second pattern focuses on situations in which others are in perceived need of protection and care. Sharon wishes to protect, but does so in ways that are not entirely reality-based and with much self-doubt. This pattern is associated with anxiety about the well-being of others that is especially intense when they are at a distance (e.g., health concerns when father travels; prior plan to pay her older, fully-employed sister to make meals for her and new husband when contemplating moving out to be married).

In addition to "making sense" of affective symptoms, Sharon's patterns also help elaborate on the specific nature of the personality disorder labels identified by her intake 
measures. Avoidant, self-defeating, and paranoid themes all have relevance to the recurrent interpersonal and intrapsychic patterns in Table 1.

$\underline{\text { Step Two: Linking past and present: Sharon's Copy Processes }}$

Our review and SASB-coding of available materials suggests that Sharon's father and mother are both key attachment figures and that the learning history with each of them is highly relevant to an understanding of her current patterns.

Patterns with Father: Sharon's father is older than her mother and the marital relationship is described as poor. As has been noted, Sharon worries for his health and safety, despite having little apparent need to be worried. In relation to her father, she describes getting along "very well" "we're very close" "I'm his little girl." But also that "he's very overprotective" and that she wishes at times that she had distance from him. Sharon knows a great deal about marital difficulties because her father is described as having poor boundaries, often confiding in Sharon about their marriage. She reports father has trouble letting things go, e.g., holding grudges for people who he feels have hurt him, and also to have had "mild depression" (for which he received medication and psychotherapy for an extended period) after Sharon's older sister left for college. Regarding holding on to things, she notes that he keeps a photo of his deceased sister with him since her death over a year ago. Sharon reports her father wants his daughters to marry, but also complains that he will never see them again if they marry.

Copy Processes Inferred with Father: From the above we determine that likely copy processes with father include identification in that he and Sharon are both deeply affected by, and fearful of, losses and transitions; they also do not easily let go or move on (SASB: $\underline{\text { Sulk and }}$ Control). They each handle conflict in indirect and problematic ways that include passivity coupled with, resistance or reactivity to loved ones who are perceived as controlling (SASB: $\underline{\text { Sulk}}, \underline{\text { Separate, }}$ Wall-Off). They are each "overprotective" in the sense of worrying over the health and well-being of others in unhelpful ways (SASB: Protect or Control, in complex combination with Ignore).

Recapitulation of the relationship with father can also be seen in part by continuing to stay close to him, watching out for him and serving as his confidante, and also by perceiving caring others as being like him: controlling or overprotective, and wishing to take distance. It is not clear the degree to which father's ambivalence about "losing" his daughters to their other relationships played into Sharon's decision to cancel the wedding. However, she shows repeated examples of being loyal to one relationship, including at her own expense, in order to be loyal to another one. Examples include the change in her email address mentioned earlier. It also includes a time early in the relationship with ex-fiancé when he complained that she chose her friends over him, and so she insisted on spending more time with the friends (to ex-fiancé: Separate, Self-Neglect; to friends: Protect). Introjection of this relationship is evidenced by Sharon's tendency to neglect her own needs in service of others (Self-Neglect) and perhaps also her reported sense of feeling like a child at work.

Potential Copy Processes with Mother. An area of potential exploration to further understand this pattern might include history of likely triangulation given Sharon's role as father's confidante about problems with mother. Late in therapy she characterized her mother as 
controlling ("Queen of the house") and her father as a subservient "vassal." Despite characterization of her and her mother as "getting along pretty well," Sharon goes on to say they are not open about "very personal things" and gives examples of refusing to have contact with mother for weeks after they have a conflict. Health concerns are also potentially salient as her mother had breast cancer and a successful mastectomy three years ago. The primary copy process suggested in Sharon's relationship with her mother includes recapitulating a pattern of cutting off relatedness in response to conflict. More detail about the maternal relationship is needed, but it is possible that the cutting off of contact occurs when mother (and now others) are perceived as too intrusive or controlling: Wall-Off in response to Control).

Potential Copy Processes with Ex-Fiancé._Sharon describes her ex-fiancé in ways that suggest he may also have been internalized as a key figure, as is often the case with anyone who is "close to the heart" (not just childhood caregivers). In relation to her ex-fiancé, she may be recapitulating her pattern of worrying about him as a way of keeping psychic proximity (enhanced by copy process patterns already noted with father). Her current self-blame may also reflect, or at a minimum feel confirmed by, his anger at her. Fear about what his anger may say about her, coupled with the desire for continued proximity may be a good way to frame her obsessive focus on the emails she receives, especially in light of the accumulated learning history internalized in her family of origin. Additional conversation with Sharon would be needed to confirm the ex-fiancé's salience as an attachment figure in his own right.

Links Between Sharon's Copy Process Patterns and Presenting Symptoms. In terms of links between copy processes and symptoms, anxiety is an affective state that enhances mobilization to deal with threat, while anger is closely related and tends to seek interpersonal outcomes involving either control or distance (Benjamin, 2003/2006). These affective states make sense for Sharon as she tries to manage conflict by cutting off relatedness with those she loves (likely hoping they will relent, comply, and return to relatedness), a strategy that might be called "winning by losing." She is also anxious about the well-being of others, including their reactions to her distance. Guilt, sadness, and depression additionally make sense as she observes how her own rejection of others lead to deep losses.

Links Between Sharon's Copy Process Patterns and Personality Disorder (PD) Prototypes. Critchfield et al. (2015) reported a method for displaying copy process links identified in IRT case formulations as an array of SASB codes identified as present (or not) for key IRT formulation elements. As shown for Sharon's formulation in Table 2, these include: behavior of others (i.e., "input" elements) as well as for the self / me (i.e., "response" elements) in two contexts: (1) early learning with loved ones, and (2) the present (including introjective self-treatment, or "impact on self" elements).

The value of this display is that it allows direct comparison of an individual's SASBbased formulation "schematic" derived from clinical narratives with parallel theory articulated by Benjamin (1996). Each of the DSM-IIIR/DSM-IV PDs was characterized by Benjamin in terms of the impact that prototypic interpersonal learning histories have on present functioning via copy process theory and SASB. An individual's case formulation array can be correlated with a parallel array for each of the prototypic personality profiles to determine the degree of fit to each PD prototype. The method has been explored extensively in recent work by Panizo 
(2020) who was able to validate Benjamin's theory of PD with respect to expected patterns of comorbidity in light of shared, SASB-defined interpersonal features in a sample of inpatients $(N$ =92) who were referred for IRT consultative interviews.

Using this method for matching individual profiles to SASB-based PD prototypes, Sharon's patterns show greatest overlap with Avoidant $(r=.49)$, and Obsessive-Compulsive $(r=$ .49) PD patterns. Narcissistic $(r=.43)$ and Passive-aggressive $(r=.41)$ show additional, notable overlap.

\section{TREATMENT IMPLICATIONS}

\section{Therapy Goals, Principles, and Procedures in IRT}

Adherence to IRT principles requires careful attention to patterns in the case formulation, not just to understand current symptoms and problems, but also to chart a course to the therapy goal region defined earlier within the SASB model (i.e., baseline of friendliness, reciprocity of focus, and ability to be moderately inter- or independent in ways that are contextually appropriate). A patient's deep awareness of copy process patterns and the factors that maintain them brings with it the possibility of choosing differently. Optimally those choices involve fostering more adaptive ways of being and in general pursuing Green states over Red. Benjamin provides a sample "speech" as a template for demonstrating how the therapy goals might be framed in language drawn directly from the SASB model (and its affective and cognitive parallels):

The goal of this therapy is to help you learn to relate to yourself and others in friendly and balanced ways that are neither too controlling nor too compliant nor too disconnected. Examples of goal behaviors are: Affirm others and yourself. Disclose honestly to yourself and loved ones. Love others and accept love from them. Love yourself too. Protect loved ones and yourself. Trust. The goal ways of relating tend to be associated with feeling that you can: accept, love and nurture. You can be: centered delighted and hopeful. The goal ways of relating tend to be associated with thinking that you can: understand, enhance, and concentrate. You can be: expressive, optimistic, and well-directed. (Benjamin, 2003/2006, Table 5.1, p. 162).

The following behaviors, if present, should become less likely: Ignoring the interests and well-being of others or self; walling off from others; attacking others or self; recoiling from others; blaming others or self; sulking; extreme tendencies to control, to submit or to distance from others. To the extent that these behaviors change, associated feelings should diminish: These include tendencies to: disregard, hate, or scorn others. To be: alienated, terrified, or agitated. To the extent that these behaviors change, associated ways of thinking should diminish. These include tendency to: distract, destroy, or condemn others. To be: scattered, shut down, or secretive. (Benjamin, 2003/2006, Table 5.2, p. 163)." 
Benjamin provides similar templates for discussion of the tasks of therapy as they involve internalized copy process patterns, gifts of love, and more.

In general terms, procedurally, IRT therapists seek to enhance patient awareness of their patterns, including where or with whom they were learned, and what purposes they play in the present. When copy process is apparent, IRT therapists help patients differentiate from the internalized "family in the head" sufficient to choose differently. Problem patterns such as selfharm, suicidality, or sabotage of self and/or relationships are blocked while internal permission is increasingly wrested to establish new, adaptive ways to be, feel, and think about self and others in the present. IRT therapists are free to select, or even create the specific interventions, techniques, strategies, or relational frames needed to accomplish these aims. As a result, the optimal treatment looks a bit different in its details for each patient. The specific interventions an IRT therapist selects will also vary as a function of the patient's stage of change with regard to the GOL and its associated behaviors. In most cases, the process of giving up on old hopes of finally "making it" with caregivers can be immensely difficult and entail a grieving process in relation to those loved ones before finally and fully adopting new ways. Guidance for how to anticipate and safely work through that longer-term process of personality reconstruction is provided with detailed case examples by Benjamin (2018).

As is evident, a full detailing of procedures and processes used in IRT treatments is beyond our present scope. However, the optimal approach always and necessarily traces back to the case formulation. The general trend is for hostility to be replaced by a baseline of friendliness that is contextually appropriate, and that may involve needing to get distance from some current figures as well as problematic internalized relationships. Alienated or distant patients likely need to learn to trust and practice greater enmeshment/engagement, while deeply enmeshed patients need support for autonomy. Still others, like Sharon, require a delicate dance involving healthy forms of both enmeshment and independence, rather than configurations involving complexity and polarized extremes of those same behaviors in different contexts.

IRT "rules of engagement" can be described as a set of principles and processes that include a core algorithm of the recommended therapist stances in every session. These include: (a) accurate empathy, (b) support for Green more than for Red, (c) use of the case formulation with every intervention, (d) tracking of interpersonal patterns (via input, response, and impact on self), (e) awareness of patient affect, behavior, and cognition, and (f) relate interventions to one of the five basic steps or tasks of the therapy process: (1) Collaboration, (2) Learning about Patterns, (3) Blocking Maladaptive Patterns, (4) Enabling the Will to Change, and (5) Learning New Patterns. A reliable measure of IRT adherence incorporates these elements. Later we describe ongoing research that has been successful in demonstrating empirical links between IRT adherence, patient progress relinquishing the GOL, and eventual outcome of long-term treatment for patients characterized by high levels of comorbidity, severity and complexity.

\section{Implications for Sharon's Case}

In the ideal IRT therapeutic process with Sharon, it would be important to establish collaboration around the task of helping her learn about and understand her Red patterns and their origins in close attachment relationships. Once she begins to recognize her patterns, she can 
then begin to explore how and why they are maintained in the present. The treatment process could then unfold as outlined above. Copy process patterns can and often do emerge in the therapeutic relationship with the therapist just as they do with other important relationships and domains of life. In practice, the optimal set of interventions attend to in-session processes as well as external events in ways that reflect and draw attention back to the case formulation.

Step Three: Extending the IRT Formulation by Exploring the Gift of Love Hypothesis for Sharon

IRT asserts that a key mechanism that often maintains problem patterns is attachmentbased motivation to finally receive love and understanding from internalized family in the head, in other words, the Gift of Love. Unfortunately, there was little or no direct information about this topic available in the materials to which we had access. As a set of hypotheses, however, some likely starting points to explore collaboratively with Sharon about her perceptions and motivations include the following possibilities:

(1) By repeating father's patterns in relation to her, and in relation to his conflicts with her mother, she shows she is "on his side" "I'm his little girl" (and contrasts older sister's approach to him). She stays loyal by choosing him over ex-fiancé when pressed; father complains he fears losing her to marriage; like him she also does not "move on" easily. Her GOL may thus be reflected in loyalty to his ways and values, which includes neglect of her own needs.

(2) By maintaining focus on her ex-fiancé Sharon keeps the attachment with him alive while preventing new ones from developing (this also partly resolves the betrayal and/or loss she may feel if she were to "move on" from father). Sharon sees that her ex-fiancé has been impacted by her choice to end the relationship, and thus learns she is important to him. Again, to receive love, she finds she must leave the person she wants the love from, and so engages in a frustrating dance of simultaneous withdrawal/rejection and obsessive mental enmeshment with her ex-fiancé.

(3) Mother: this relationship in particular needs further exploration to be fully understood. A gift of love is suggested in her repeated experience of others as intrusive/controlling, to which she responds with distance, invoking the same pattern that was present early on with mother (while also potentially identifying with father, who appears to have had the same set of patterns in relation to mother).

The GOL hypothesis, to be effective as an intervention, must never be imposed on patients, but is instead offered as a possibility that is consistent with principles of human evolution and development, and that may apply especially if it is credibly supported by patient impressions of the context and meaning of copy process links. If the GOL can be named and agreed upon by patient and therapist, it offers a great deal of potential leverage for the therapeutic process. As this attachment-linked motivation to persist in Red behaviors is faced and the yearning for love and approval is reworked or let go, then a patient is freer to choose and practice more adaptive options in the present. 
Step Four: Some Recommended Therapeutic Tasks and Goals for Sharon via IRT formulation

In IRT, pattern-recognition and motive-exploring therapeutic activities create awareness of "how it works" so that a real choice about change can become possible, along with a reasonable sense of what it will require. In Sharon's case, as with many therapy processes, careful rapport building and intentional collaborative planning would be essential. Her patterns suggest that Sharon is reactive to control and vacillates between distance and enmeshment when the perceives it. Her therapist must approach work with her carefully and invite her to consider her patterns and gain insight, rather than pronouncing interpretations that could easily be experienced as controlling (this appears to have occurred in the actual treatment process she experienced in the original study). Prior treatment attempts appear to have borne this out, with her leaving more than one therapy feeling misunderstood in being told to "move on" from her ex-fiancé. Their recommendation was reasonable in some respects, but it also missed the developmental, identity, and meaning-based contexts for her bondedness to the pattern. It misses how the problem is also an attempt to adapt and find solutions to dilemmas of the present, even if it invokes old maladaptive strategies and views.

Using a collaborative, compassionate and patient process, Sharon's case formulation suggests the need to attend to the following:

(1) The strategy of "winning by losing" should be explored to understand it with more clarity than is possible from the limited available database (her therapist did not pursue this pattern in ways that would be considered adherent to IRT principles). This might involve tracing where this was learned developmentally, how Sharon has used it to cope in other situations, and how it is functioning presently. Techniques of motivational interviewing may be helpful for considering alternatives that involve more self-assertion and direct communication.

(2) Consider ways in which Sharon's current patterns reflect loyalty to her father and his ways of being. This might include tracing of potential parallels in the conflict between her parents, and those found in her own relationships. She may be invited to differentiate from these old patterns be envisioning and practicing healthier relational alternatives or conflict resolution strategies.

(3) Once a working therapeutic relationship is established, and Sharon has greater insight about her patterns and their origins, it might be helpful to suggest that she engage in a form of couples therapy with her ex-fiance if this is of interest to both of them. If rapprochement is not feasible or desired, then Sharon might be able to explore her patterns and their relevance to this relationship through variations on two-chair work.

\section{$\underline{\text { Poor IRT Adherence in Sharon's Actual Treatment }}$}

Unfortunately, the actual process of treatment for Sharon appears not to have unfolded in helpful ways. While she did not terminate prematurely, Sharon reported little benefit. From review of transcripts, what appears instead is a pattern of periodic alliance ruptures that did not have effective repair. In our view, many of these took the form of relational / transference interpretations that appeared forced and were often poorly aligned with what Sharon had been 
emphasizing prior to that point. Sharon's therapist often appeared to control the process of therapy by presenting his take on her situation in a relatively confrontational manner and offer interpretations that were critical in content. In keeping with her formulation Sharon reacted to him with compliance at times, and defiance at other times. The resulting process would likely receive critique from most school-based approaches.

Striking to us is how the therapist's input often invited comparison to the intrusive control and misunderstanding that Sharon reported in her other important relationships. In other words, copy process repetitions were in evidence in the therapy process, but were not effectively identified or managed. An example of enacting the old patterns is apparent in their second session, with other examples found in additional transcript segments and written summaries of session content available in the archive, such as the one provided below. Interestingly, the therapist appears to have caught on to some of the themes captured in the IRT case formulation, such as the tendency to comply or please others ambivalently, but uses an ineffective process to explore them:

The therapist then inquires whether the relationship was sexual or not and the patient states that it was. The therapist then proceeds to probe heavily into the nature of the sexual relationship and into whether she was truly satisfied or whether she was simply accommodating her boyfriend. The therapist proceeds to ask whether or not she had orgasms or if she enjoyed it all. The patient admits that although she did enjoy their sexual relationship but that she "was happy if he was happy." The therapist reiterates that this reveals her accommodating nature and links this pattern to the negotiation that occurred before as to who should begin the session. Patient changes the subject back to how the boyfriend liked it when she would initiate sex and how he was a good friend even though he was erratic sometimes. The therapist then encourages her to take responsibility for her part in the relationship and asks: "did you have any part in evoking his erratic side to come forth?" The patient shrugs the responsibility at first and the therapist probes again "here's a guy who you said you have the deepest connection with but that you would put him second to your friends?" Patient responds that really she would like to put everyone first but cannot and this causes conflict for her in relationships. The therapist challenges her again to take responsibility by stating "yeah but you had a plan with him and you would push him aside," and continues by stating that she sounds very controlling and withholding in regards to him. Patient rebuffs by saying "he wanted to control me." Therapist probes further and patient then responds that "okay, it could be some of my fault."

SASB codes of the therapist's interventions characterize them as fairly saturated with Control, Ignore, and Blame, especially relative to a typical therapeutic baseline. This central pattern in her case formulation plays out repeatedly throughout the course of the therapy process, frequently resolving when Sharon seems to give in and say that she agrees. The therapeutic process thus appeared to enact and repeat her central copy process themes in vivo, and so, predictably, affects of anxiety, anger, and guilt persisted. Henry, Schacht, \& Strupp (1986, 1990) 
noted that such replications in the therapeutic relationship serve to reinforce negative introjects. Similarly, the empirical literature around transference interpretation supports the importance of both accuracy and specificity of interpersonal content in links to outcome (Crits-Christoph \& Connolly Gibbons, 2001; Norville, Sampson, \& Weiss, 1996).

Measuring Adherent Use of Principles in Context of Individual Formulations as a Way Forward for Research

We believe an alternate approach was needed to work with Sharon, one that not only attended to their alliance and collaboration toward shared goals, but one that could credibly help her come to terms with maladaptive ways and values internalized in close attachment relationships. Our current goal with IRT is to follow up on a sample of CORDS cases of similar formulation complexity to Sharon. Preliminary findings have shown that adherent use of patient case formulations are linked to outcome, and that the link is mediated by changes in patient GOL (Critchfield, Dobner-Pereira, Panizo, \& Benjamin, 2019). In other words, for "stuck," "complex," "non-responder" cases, progress coming to terms with internalized attachment figures is a key mechanism of change. These findings support use of an IRT case formulation with patients like Sharon.

\section{REFERENCES}

Benjamin L. S. (1979). Structural analysis of differentiation failure. Psychiatry: Journal for the Study of Interpersonal Processes 42(1):1-23. doi: 10.1080/00332747.1979.11024003

Benjamin, L. S. (1986). Adding social and intrapsychic descriptors to Axis I of DSM-III. In T. Millon \& G. L. Klerman (Eds.), Contemporary directions in psychopathology: Toward the DSM-IV. (pp. 599-638). The Guilford Press.

Benjamin, L. S. (1996). Interpersonal diagnosis and treatment of personality disorders (2nd ed.). New York, NY: Guilford.

Benjamin, L. S. (2000). SASB Intrex user's manual for short, medium and long form questionnaires. Salt Lake City: University of Utah.

Benjamin L. S. (2003/2006). Interpersonal Reconstructive Therapy: Promoting change in nonresponders. New York, NY: Guilford Press.

Benjamin, L. S. (2008). What is functional about functional autonomy? Journal of Personality Assessment, 90(5), 412-420.

Benjamin L. S. (2018). Interpersonal Reconstructive Therapy (IRT) for anger, anxiety and depression: It's about broken hearts, not broken brains. Washington, D. C.: American Psychological Association.

Benjamin, L. S., \& Cushing, G. (2000). Reference manual for coding social interactions in terms of Structural Analysis of Social Behavior. Salt Lake City: University of Utah.

Benjamin, L. S., Rothweiler, J. C., \& Critchfield, K. L. (2006). The use of Structural Analysis of Social Behavior (SASB) as an assessment tool. Annual Review of Clinical Psychology, 2, 83-109.

Critchfield, K. L. \& Benjamin, L. S. (in preparation). Structural Analysis of Social Behavior (SASB): A primer for clinical use. APA press.

Critchfield, K. L., Benjamin, L. S., \& Levenick, K. (2015). Reliability, sensitivity, and specificity of case formulations in Interpersonal Reconstructive Therapy: addressing 
psychosocial and biological mechanisms of psychopathology. Journal of Personality Disorders, 29(4), 547-573.

Critchfield K. L., Davis, M. J., Gunn, H. E. Benjamin, L. S. (2008, June). Measuring therapist adherence in Interpersonal Reconstructive Therapy (IRT): Conceptual framework, reliability, and validity. Poster presented to the International Society for Psychotherapy Research; Barcelona, Spain.

Critchfield, K. L., Dobner-Pereira, J., Panizo, M., \& Benjamin, L. S. (2019, August). The Gift of Love as a key mechanism of change in Interpersonal Reconstructive Therapy. Paper presented as part of a panel titled "Effective Psychotherapy Using Principles from Attachment Theory and Developmental Psychopathology" (Lorna Smith Benjamin, chair) to the American Psychological Association, Chicago, IL.

Critchfield, K. L., Mackaronis, J. E., \& Benjamin, L. S. (2017). Characterizing the integration of CBT and psychodynamic techniques in interpersonal reconstructive therapy for patients with severe and comorbid personality pathology. Journal of Psychotherapy Integration 27(4): 460-475. doi: 10.1037/int0000092.

Critchfield, K. L., Panizo, M. T., \& Benjamin, L. S. (2019). Formulating key psychosocial mechanisms of psychopathology and change in Interpersonal Reconstructive Therapy. In U. Kramer (Ed.), Case formulation for personality disorders: Tailoring psychotherapy to the individual client (181-201). Cambridge, MA: Academic Press. doi: 10.1016/B978-012-813521-1.00010-2.

Crits-Christoph, P., Connoly Gibbons, M. B., Temes, C. M., Elkin, I., \& Gallop, R. (2010). Interpersonal accuracy of interventions and the outcome of cognitive and interpersonal therapies for depression. Journal of Counseling and Clinical Psychology, 78 (3), 420428.

Henry, W. P., Schacht, T. E., \& Strupp, H. H. (1986). Structural analysis of social behavior: Application to a study of interpersonal process in differential psychotherapeutic outcome. Journal of Consulting and Clinical Psychology 54(1): 27-31. doi: 10.1037/0022006X.54.1.27.

Henry, W. P., Schacht, T. E., \& Strupp, H. H. (1990). Patient and therapist introject, interpersonal process, and differential psychotherapy outcome. Journal of Consulting and Clinical Psychology, 58(6), 768-774. doi: 10.1037/0022-006X.58.6.768

Karpiak, C., Critchfield, K. L., \& Benjamin, L. S. (2011, June). Empathy, adherence, and outcome in Interpersonal Reconstructive Therapy with treatment-resistant patients. Paper presented to the Society for Psychotherapy Research, Bern, Switzerland.

Norville, R., Sampson, H., \& Weiss, J. (1996). Accurate interpretations and brief psychotherapy outcome. Psychotherapy Research 6(1), 16-29.

Panizo, M. (2020). An Interpersonal View of Personality Disorders. Dissertation. James Madison University.

Westerman, M. A., \& Critchfield, K. L. (2021). Goals and design of the project and basic information about Sharon's case. Pragmatic Case Studies in Psychotherapy. 


\section{Table 1: Summary of Current Patterns with SASB-Based Descriptors}

Legend: SASB-based pattern analysis of Sharon's relational descriptions and their links to symptoms are shown. The information is organized by perceived inputs from others/world, her reported responses to them, and self-concepts associated with each identified problem or symptom.

\begin{tabular}{|c|c|c|c|}
\hline Input $\rightarrow$ & Response $\rightarrow$ & Impact on Self: & $\begin{array}{c}\text { Associated } \\
\operatorname{Symptom}(s):\end{array}$ \\
\hline $\begin{array}{l}\text { 1. Loved ones are } \\
\text { perceived as } \\
\text { controlling, } \\
\text { judgmental, intrusive, } \\
\text { not understanding her } \\
\text { needs even when } \\
\text { combined with love or } \\
\text { concern for her. } \\
\text { (Control + Ignore, } \\
\text { Blame + Ignore, } \\
\text { Protect + Blame) }\end{array}$ & $\begin{array}{l}\text { 1. Feels misunderstood, } \\
\text { angry. Complies } \\
\text { resentfully, defies } \\
\text { indirectly, and withdraws } \\
\text { herself. Withdrawal is seen } \\
\text { as primary way of } \\
\text { punishing or coercing } \\
\text { others in response to } \\
\text { conflict } \\
\text { (Sulk, Separate, Wall-Off) } \\
\text { (Control + Ignore, } \\
\text { Blame + Ignore) }\end{array}$ & $\begin{array}{l}\text { 1. Deprives herself } \\
\text { of valued } \\
\text { relationships (Self- } \\
\text { Neglect), wonders } \\
\text { what is wrong with } \\
\text { her that she is } \\
\text { treated this way } \\
\text { (Sulk }+ \text { Self-Blame). }\end{array}$ & $\begin{array}{l}\text { 1. Anger; Guilt (that } \\
\text { indirectly indicts } \\
\text { others); Anxiety as } \\
\text { she mobilizes to } \\
\text { prevent loss and, } \\
\text { helplessness (cannot } \\
\text { "move on"). }\end{array}$ \\
\hline $\begin{array}{l}\text { 2. Loved ones } \\
\text { perceived as confiding } \\
\text { in and relying on her } \\
\text { ( } \underline{\text { Trust) }}\end{array}$ & $\begin{array}{l}\text { 2. Perceives self as focused } \\
\text { on meeting the needs of } \\
\text { others, monitors and } \\
\text { worries about them (often } \\
\text { unrealistically or from a } \\
\text { distance: Protect + Ignore) }\end{array}$ & $\begin{array}{l}\text { 2. Anxiety is } \\
\text { oriented to } \\
\text { caregiving; fears } \\
\text { failing others (Self- } \\
\text { Blame). }\end{array}$ & $\begin{array}{l}2 . \text { Anxiety (oriented } \\
\text { to maintaining } \\
\text { proximity and well- } \\
\text { being of loved ones). }\end{array}$ \\
\hline
\end{tabular}


The Case of Sharon Considered from the Vantage Point of Interpersonal Reconstructive Therapy

K.L. Critchfield, J. Dobner-Pereira, \& E. Stucker

Pragmatic Case Studies in Psychotherapy, http://pcsp.libraries.rutgers.edu

Volume 17, Module 1, Article 4, pp. 42-62, 04-19-21 [copyright by author]

Table 2: Sharon's Case Formulation Arrayed as the Set of SASB-Defined Behaviors Involved in Her Symptom-Linked Copy Process Formulation

\begin{tabular}{|c|c|c|c|c|c|}
\hline \multirow[b]{2}{*}{ SASB Code } & \multicolumn{2}{|c|}{ Others to Me } & \multicolumn{2}{|c|}{ Me to Others } & \multirow{2}{*}{$\begin{array}{c}\text { Me to Me } \\
\text { Introject }\end{array}$} \\
\hline & Past & Present & Past & Present & \\
\hline Emancipate & 0 & 0 & 0 & 0 & 0 \\
\hline Affirm & 0 & 0 & 0 & 0 & 0 \\
\hline Active Love & 0 & 0 & 0 & 0 & 0 \\
\hline Protect & Present & Present & Present & Present & 0 \\
\hline Control & Present & Present & 0 & Present & 0 \\
\hline Blame & Present & Present & 0 & Present & Present \\
\hline Attack & 0 & 0 & 0 & 0 & 0 \\
\hline Ignore & Present & Present & 0 & Present & Present \\
\hline Separate & 0 & 0 & 0 & 0 & \\
\hline Disclose & 0 & 0 & 0 & 0 & \\
\hline $\begin{array}{r}\text { Reactive } \\
\text { Love }\end{array}$ & 0 & 0 & 0 & 0 & \\
\hline Trust & Present & 0 & 0 & 0 & \\
\hline Submit & 0 & 0 & 0 & 0 & \\
\hline Sulk & 0 & 0 & 0 & Present & \\
\hline Recoil & 0 & 0 & 0 & 0 & \\
\hline Walk-Off & 0 & 0 & Present & Present & \\
\hline
\end{tabular}


Pragmatic Case Studies in Psychotherapy, http://pcsp.libraries.rutgers.edu

Volume 17, Module 1, Article 4, pp. 42-62, 04-19-21 [copyright by author]

Figure 1. The Simplified SASB Cluster Model.

(Figure 3.9 on p. 55, Benjamin, L. S. (1996). Interpersonal Diagnosis and Treatment of Personality Disorder. NY: Guilford Press. $2^{\text {nd }}$ ed. Reprinted with permission of Guilford Press.)

Note: In the figure, the OTHER, $\underline{\mathrm{SELF}}$, and INTROJECT foci are represented respectively from top to bottom by the three words that appear one under the other in each cluster.

\section{EMANCIPATE}

\section{SEPARATE}

\section{SELF-EMANCIPATE}

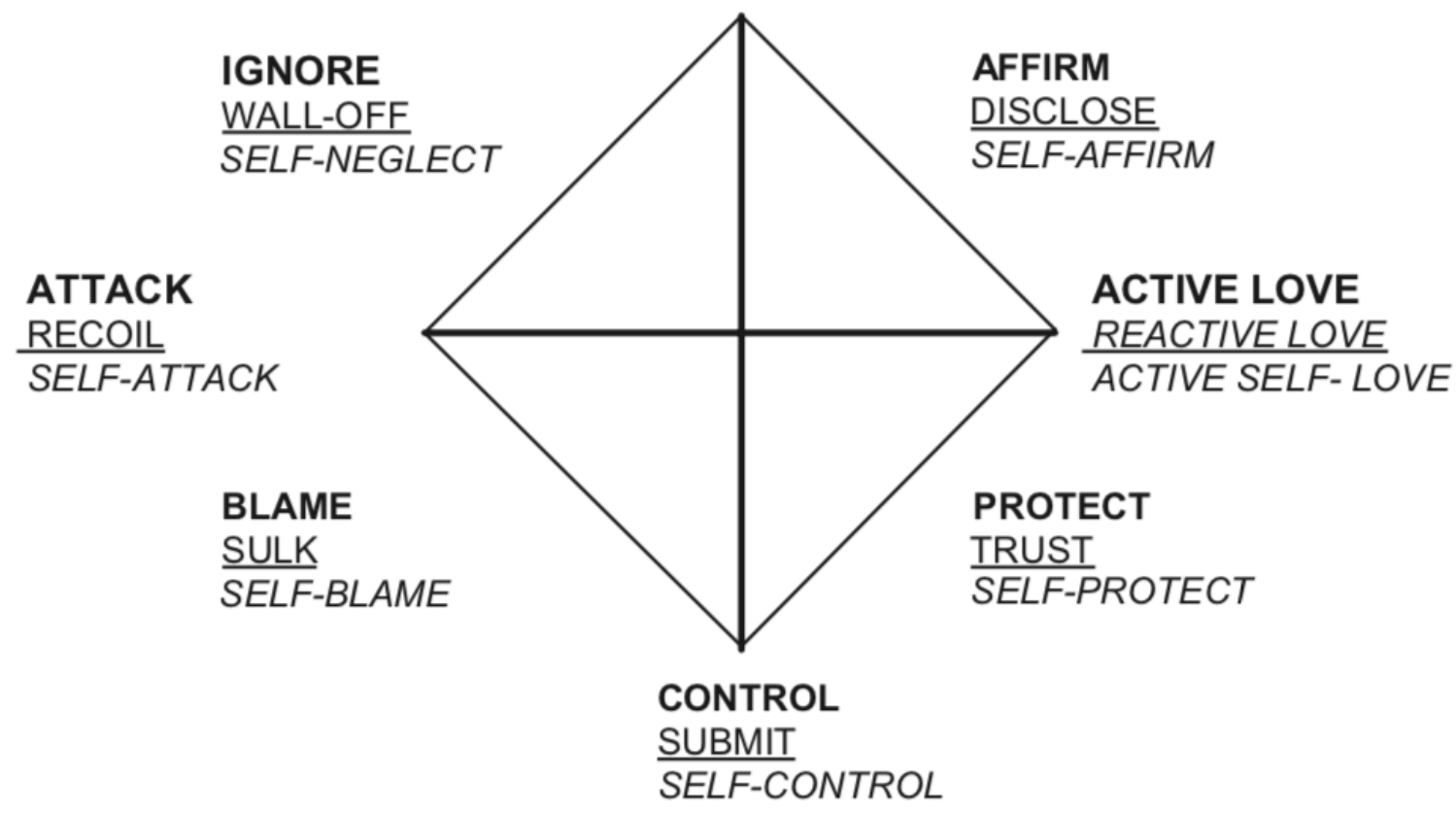

